\title{
Semi-Quantitative Risk Assessment Method for Groundwater Source Protection using a Process- Based Interdisciplinary Approach
}

Robert Duda ( $\sim$ duda@agh.edu.pl )

AGH University of Science and Technology https://orcid.org/0000-0003-2298-2351

Robert Zdechlik

AGH University of Science and Technology

Jarosław Kania

AGH University of Science and Technology

\section{Research Article}

Keywords: water supply, risk analysis, wellhead protection area, contaminant source, groundwater pollution, land use

Posted Date: May 24th, 2021

DOl: https://doi.org/10.21203/rs.3.rs-412818/v1

License: (c) (1) This work is licensed under a Creative Commons Attribution 4.0 International License. Read Full License

Version of Record: A version of this preprint was published at Water Resources Management on July 20th, 2021. See the published version at https://doi.org/10.1007/s11269-021-02898-0. 


\title{
Semi-Quantitative Risk Assessment Method for Groundwater Source Protection using
}

\section{A Process-Based Interdisciplinary Approach}

\author{
Robert Duda $^{1 *}$, Robert Zdechlik ${ }^{1}$, Jarosław Kania ${ }^{1}$
}

${ }^{1}$ AGH University of Science and Technology; Faculty of Geology, Geophysics and

Environmental Protection, Mickiewicza 30, 30-059 Kraków, Poland.

*duda@agh.edu.pl

ORCID:

R. Duda: 0000-0003-2298-2351;

R. Zdechlik: 0000-0003-2808-0527

J. Kania: 0000-0003-2459-0060

\begin{abstract}
Potable groundwater resources are under threat as a result of industrial development and an increase in fertilizer use. The protection of groundwater supply may require the establishment of groundwater source protection zones (GSPZ) to allow protective measures. The aim of this study has been to develop a new approach to groundwater source risk assessment (GSRA). The risk has been defined as the greatest of the risks identified for individual potential sources of contamination (PSCs). The risk resulting from a PSC is the combination of its adverse impact on groundwater, unwanted event probability, its adverse effect and annoyance for the population. A multi-criteria assessment has been designed to estimate the indices of potential groundwater impact of industrial facilities and non-inert waste landfills, using the range and weight method. The application of the approach proposed has been tested on an idealized model under three scenarios, involving various industrial PSCs and fertilization. The overall nitrogen load was compared to the maximum effective nitrogen load for the crops in question. The sensitivity analysis conducted for this methodology has revealed that the main factors affecting the risk to water supply are non-reactive
\end{abstract}


contaminant mass load in PSC leachate and the ratio of groundwater volume abstracted from the wells to the amount of water flowing from PSCs to the wells, which determine the dilution degree of contaminant mass. This proposed interdisciplinary approach to GSRA should provide a robust basis for making decisions about GSPZ establishment and for the development of a groundwater risk analysis methodology.

\section{Keywords}

water supply, risk analysis, wellhead protection area, contaminant source, groundwater pollution, land use

\section{INTRODUCTION}

Groundwater contamination risk analysis is a basic part of the process of assessing the necessity of undertaking potential protective measures on a regional scale, mainly with respect to catchment areas. However, a particularly important type of analysis of groundwater contamination risk combined with human health risk are analyses concerning water sources. These analyses are performed in order to assess the need for groundwater source protection zone (GSPZ) establishment, and for setting up pollution prevention measures. WHO (2017a) recommends that a drinking water safety plan and risk management system be developed in order to manage groundwater resources. This is necessary for preventing possible hazards within the wellhead protection area (WHPA).

Groundwater source risk assessments (GSRAs) are performed on the basis of analyses of the impact of land use (Huan et al. 2018; Li et al. 2018). Land use forms potentially threatening the quality of abstracted groundwater mainly include agriculture and point sources of contamination. In relation to agricultural impact, risk analysis was conducted for nitrate pollution (Su et al. 2013; Teng et al. 2019). In addition to qualitative methods for estimating groundwater risk (Li et al. 
2015; Zhang et al. 2016; Duda et al. 2020), advanced methods such as numerical modelling of mass transport through the vadose zone and the saturated aquifer were used (Troldborg et al. 2009; Enzenhoefer et al. 2012; Huan et al. 2015, 2020; Locatelli et al. 2018). Enzenhoefer et al. (2015) presented a more holistic and probabilistic approach, which additionally took into account, inter alia, the aggregation of impacts from different contaminants and spill locations into cumulative impact on the risk, and a method for the stochastic nature of spill events accounting when converting the aggregated impact to a risk estimate. Furthermore, Rodak and Silliman (2012) proposed an advanced approach combining probabilistic risk analysis (PRA) with fault trees of the contamination sources, along with chemical transport modelling and human health impact to estimate the health effects for abstracted water users. The methods used in the PRA of engineering system failure scenarios have been described by Ostrom and Wilhelmsen (2019), and Modarres and $\operatorname{Kim}(2020)$.

However, it is still a problem that most GSRA approaches usually take as a basis for their assessment a specific concentration of the contaminant under analysis (for example nitrates) in groundwater, i.e., a situation that has already occurred as a result of the actual impact of pollution sources. However, these sources are usually not specified and characterized in detail. In the case of industrial facilities, the overall characterization of the facility itself is lacking, which would take into account not only technical aspects but also non-technical ones which may influence the probability of a failure. The approaches adopted to date typically still do not involve a simultaneous estimate of event probability and of the chemical compound mass emitted from a potential source of contamination (PSC).

The deficiencies identified in existing GSRAs particularly concern the estimation of the potential total effective nitrogen load for a given crop. This total mass of nitrogen will be dissolved in the water and, as nitrates, it will move to the aquifer and only then will it be transported to the water source. Thus, when analyzing the risk of nitrates reaching the well at concentrations that threaten the users' health, it is important to estimate the risk directly from PSCs, and not just the risk which 
is the observed effect of PSC impact. Furthermore, existing approaches to GSRA do not take into account the annoyance related to the adverse effect of PSC impact on the users of water.

The purpose of this article is to present a proposal for filling the indicated gaps by presenting a comprehensive and interdisciplinary approach to GSRA. Improving GSRA quality is particularly important in the context of groundwater protection given its increasing scarcity. The method proposed accounts both for those risk factors that have been previously considered by other researchers and for additional factors considered for the first time in this study. Our sourcepathway-receptor approach is a semi-quantitative and modular framework for a process-based GSRA.

\section{METHODOLOGY}

\subsection{Calculation of the degree of risk}

The method and the presented example concern a situation where a well field has a delineated GSPZ and a risk analysis is required in order to determine the necessity of its legal establishment so that a groundwater protection plan can be implemented. The purpose of implementing this plan is to eliminate the possibility of a degradation in the quality of the groundwater abstracted that would result in the discontinuation of water supply from this source to users. The GSRA method adopted is based on the assumption that at the time of the assessment, the well field is drawing uncontaminated water and no PSCs located within the GSPZ have released any contamination yet.

In the approach adopted, the greatest of the risks identified for the individual PSCs located within the GSPZ is considered to be the risk of contamination of the groundwater source:

$$
R=\max R_{i}
$$

where:

$$
R_{i}=L U_{i} \cdot P A_{i} \cdot A E_{i} \cdot A_{A E i}
$$


where $R$ is the degree of risk to the well field, $R_{i}$ is the risk caused by a given PSC, $i$ is the PSC number, $L U_{i}$ is the adverse impact of the PSC on groundwater quality, $P A_{i}$ is the probability of occurrence of the unwanted event/failure, $A E_{i}$ is the adverse effect of contaminating the aquifer and $A_{A E i}$ is the annoyance caused by the adverse effect to water users.

The main factor determining the risk to a groundwater well field from PSC impact is the adverse effect of the unwanted event. The absence of an adverse effect of a land use form is tantamount to the absence of risk to the well field from that land use form. Where a PSC causes an adverse effect, the increase in risk is affected by: (i) an increase in the severity of the adverse impact of the PSC, (ii) an increase in the contaminant emission potential; and (iii) an increase in the annoyance caused by the adverse effect.

The accepted risk classification (Table 1) also defines the rules for the establishment of a GSPZ. If the risk to a well field is found to be high, a GSPZ must be established to protect it.

Table 1. Classification of groundwater source risk

\begin{tabular}{ccc}
\hline \multicolumn{2}{c}{ Risk } & GSPZ establishment \\
\hline \hline$R=0$ & no risk present & not required \\
\hline $0<\mathrm{R} \leq 8$ & low & recommended \\
\hline $\mathrm{R}>8$ & high & required \\
\hline
\end{tabular}

\subsection{Adverse impact $(L U)$}

The degree of adverse impact of PSCs on groundwater is determined using the relevant classification (Table 2). The adverse impact of a PSC is assumed to be dependent on:

- the chemical compound mass that may be emitted from a given source;

- the concentration of chemical compounds in the leachate;

- the toxicity of the chemicals that may be emitted;

- the depth of the groundwater table;

- the degree of insulation of the PSC from the ground. 
Table 2. Adverse impact of land use forms that are PSCs on groundwater

Potential source of contamination (PSC)

Degree of impact

$(L U)$

- an above-ground liquid chemical/fuel tank

- a dry cleaner

- a transformer station

- a rubber and tire industry plant

- a paper mill

- a food processing plant

- a power plant

(medium)

- insulated from the ground: a landfill or dumping site for municipal waste, industrial waste, power plant waste,

a slag heap

- a quarry

- a livestock farm

- a below-ground liquid chemical/fuel tank, gas station

- a pipeline with liquid fuel or a chemical compound

- a railway marshalling yard

- poorly insulated from the ground: a landfill or dumping site for municipal waste, industrial waste, power plant waste, a slag heap

- a mineral heap poorly insulated from the ground

- a heap of non-inert waste rock

poorly insulated from the ground

- an abandoned mine other than a metal ore one

- a metal ore processing and enrichment plant

- an urban area with a leaky sewerage system and leaky sewerage facilities

- a cemetery

- an oil refinery, chemical plant

- an iron and steel works, metal industry plant, electroplating plant

- a tannery

- not insulated from the ground: a landfill or dumping site for municipal waste, industrial waste, power plant waste,

a slag heap

- a mineral heap not insulated from the ground

- a heap of non-inert waste rock not insulated from the ground

- a flotation tailings dam

- an oil field

- a metal ore mine abandoned by flooding

- an urban area without sewerage systems or facilities 


\subsection{Probability of an unwanted event}

An unwanted event is the worst-case emission of a contaminant to groundwater among the emissions possible for a given PSC. The probability of an unwanted event (PA) is defined in a different manner depending on the type of land use.

\subsubsection{Industrial and infrastructure facilities and installations}

The PA is determined by assessing the technical condition of the facility in question. The technical condition is determined on the basis of the age of the facility, the method of its construction, the scope and frequency of periodic checks/inspections, and the fail-safe protections used. Depending on the scenario implemented, the risk analysis may concern the current or projected technical condition.

The PA is expressed on a scale of 0 to 1 (Table 3), where a value of 0 corresponds to the impossibility of an accident/failure occurring within a 25-year horizon under any scenario considered. A value of 1 corresponds to a situation where a failure/accident will occur with $100 \%$ probability within a 25 -year horizon under at least one scenario. The span of 25 years is used because this period is adopted as a limit when delineating the range of the GSPZ based on the isochrone of the arrival of non-reactive contaminants from the land surface to the well.

Table 3. Classification of the PA for infrastructure and industrial facilities and installations

\begin{tabular}{cc}
\hline \multicolumn{2}{c}{ Probability of an unwanted event } \\
\hline $0 \leq P A \leq 0.3$ & low \\
\hline $0.3<P A \leq 0.5$ & high \\
\hline $0.5<P A \leq 0.7$ & very high \\
\hline $0.7<P A \leq 1.0$ & extremely high \\
\hline
\end{tabular}

To determine the PA for industrial and infrastructure type PSCs, a two-stage approach has been adopted (Fig. 1). Stage I consists of a qualitative assessment: if for the PSC in question, the probability of event occurrence is low $(\mathrm{PA} \leq 0.3)$, then in further stages it is assumed that there is no adverse effect $(A E=0)$ and consequently no risk to the well field $(R=0)$. If the result of this 
assessment shows that $0.3<P A \leq 0.5$, then the degree of adverse effect of the event is determined. On the other hand, if the qualitative assessment demonstrates that the probability of occurrence of an unwanted event is very high $(P A>0.5)$, then stage II of determining the PA follows (quantitative assessment).

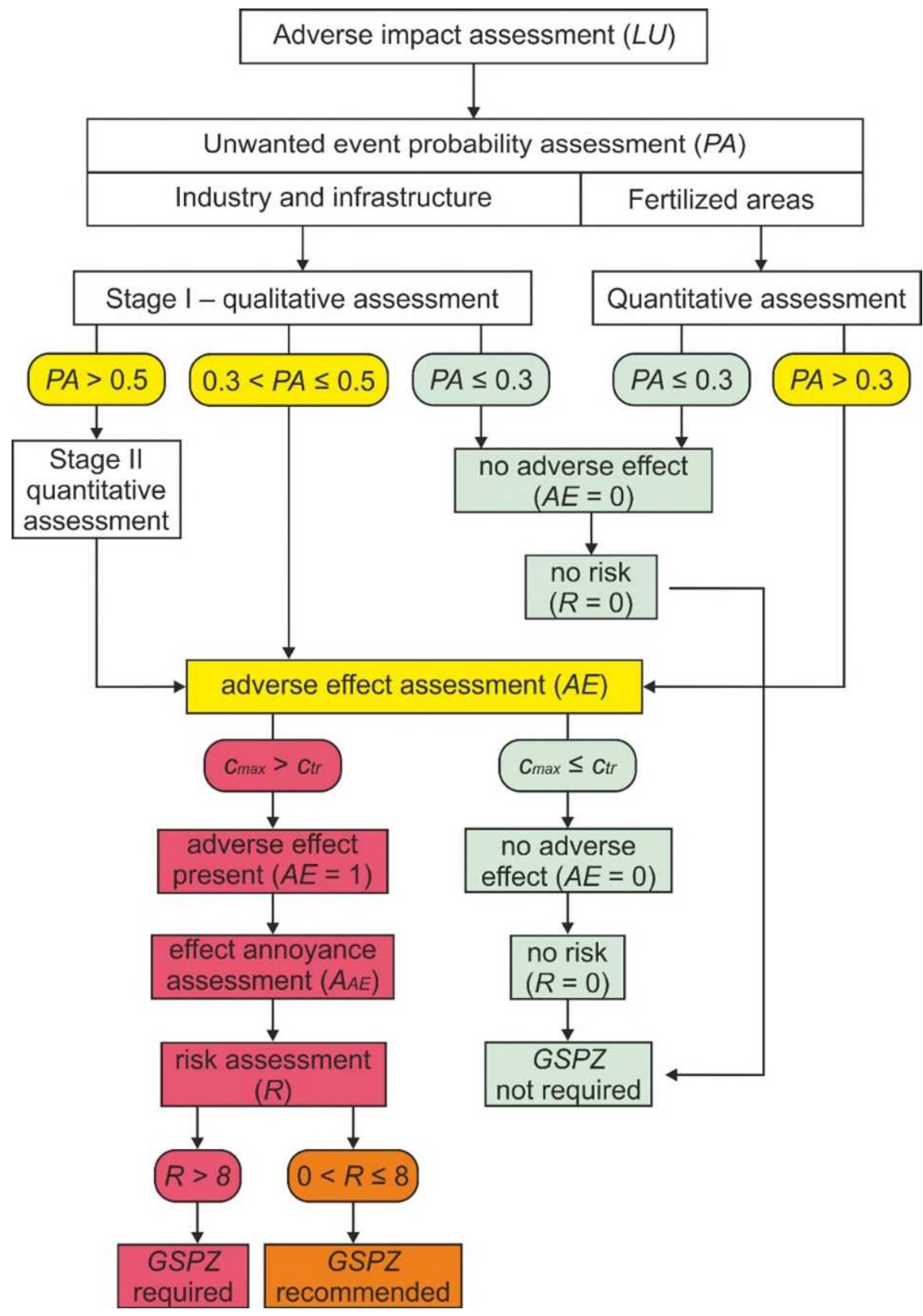

Fig. 1 Flowchart of GSRA application

\section{Step I - qualitative assessment of PA}

It has been assumed that PA of an industrial and infrastructure facility resulting in possible groundwater contamination increases as the technical condition of the facility in question 
deteriorates. The technical condition of an industrial or infrastructure facility is determined by the manner of construction of the facility and its fail-safe protections $(R)$, its operation or production technology $(T)$ and the frequency and scope of its inspections as well as the fail-safe protections and procedures to be followed in the event of an incident $(I M)$. Non-technical factors have also been taken into account in the assessment (Table 4), namely the possibility of natural $(N)$ and economic and legal $(E L)$ random events, and human error $(H)$. Natural events include geohazards, which are extreme weather events, landslides caused by natural factors, earthquakes, tsunamis, etc. Economic and legal factors include the liquidation of a company as a result of its bankruptcy, a change in business profile, a certain negligence and omission resulting from cost cutting.

Table 4. Assessment criteria and ranks of factors affecting the risk of groundwater contamination

\begin{tabular}{|c|c|}
\hline Criterion, factor & Rank \\
\hline $\begin{array}{l}\text { Construction manner } \\
\text { - } \quad \text { very careful, only proper materials used, BAT applied throughout } \\
\text { - } \quad \text { careful, inappropriate materials/technologies used in some places } \\
\text { - } \quad \text { mostly careless, inappropriate materials used frequently } \\
\text { - careless, inappropriate materials used }\end{array}$ & $\begin{array}{l}R_{r} \\
0.1 \\
0.4 \\
0.7 \\
1.0\end{array}$ \\
\hline $\begin{array}{l}\text { Technical inspections and maintenance of the facility and its safeguards } \\
\text { - very careful, only proper materials/equipment used, BAT applied throughout, } \\
\text { very frequent } \\
\text { - usually careful, inappropriate materials/equipment used in some places, } \\
\text { frequent } \\
\text { - usually careless, inappropriate materials/equipment used frequently, } \\
\text { infrequent } \\
\text { - fragmentary, sporadic }\end{array}$ & $\begin{array}{c}I M_{r} \\
0.1\end{array}$ \\
\hline $\begin{array}{l}\text { Operating or production technology } \\
\text { - very modern with BAT applied, very small amount of liquids containing } \\
\text { chemicals in circulation and solid waste } \\
\text { - modern, small amount of liquids containing chemicals in circulation and } \\
\text { waste } \\
\text { - modern, large amount of liquids containing chemicals in circulation and } \\
\text { waste } \\
\text { - obsolete, very large amount of liquids containing chemicals in circulation and } \\
\text { waste }\end{array}$ & $\begin{array}{l}0.4 \\
0.7\end{array}$ \\
\hline $\begin{array}{l}\text { Natural random event / Economic or legal random event / Human error } \\
\text { - very unlikely } \\
\text { - unlikely } \\
\text { - likely } \\
\text { - very likely }\end{array}$ & $\begin{aligned} N_{r} / E L_{r} / H_{r} \\
0.1 \\
0.4 \\
0.7 \\
1.0\end{aligned}$ \\
\hline $\begin{aligned} I_{\text {in }} & \\
& <5 \\
& -5-10 \\
& -10-15 \\
& ->15\end{aligned}$ & $\begin{array}{l}P A \\
0.2 \\
0.4 \\
0.6 \\
0.8\end{array}$ \\
\hline
\end{tabular}


Human error includes the deliberate flouting of approved procedures and norms, negligence, lack of responsibility, the lack of necessary qualifications and competences among the employees hired without complying with the relevant requirements, bending to pressure from superiors for fear of losing work, pressure on subordinates in order to force them to act improperly or to refrain from taking certain actions or reporting irregularities, group solidarity, etc.

It has been assumed that the degree of impact of individual factors determining the technical condition of industrial and infrastructure facilities varies, which is expressed by their weights from 1 to 5 . The weights adopted for individual factors are: $5\left(R_{w}, I M_{w}\right), 4\left(T_{w}\right), 3\left(N_{w}\right), 2\left(E L_{w}\right)$ and 1 $\left(H_{w}\right)$. Each factor can have a value (rank) in the range from 0.1 to 1 (Table 4). We have defined the index of potential impact of industrial and infrastructure sources on groundwater:

$$
I_{\text {in }}=R_{r} \cdot R_{w}+I M_{r} \cdot I M_{w}+T_{r} \cdot T_{w}+N_{r} \cdot N_{w}+E L_{r} \cdot E L_{w}+H_{r} \cdot H_{w}
$$

Depending on the value of the $I_{\text {in }}$ index, $P A$ is estimated for industrial and infrastructure facilities (Table 4).

For non-inert waste landfills, following the concept put forward by Zhang et al. (2016), several factors have been considered that impact the risk of groundwater contamination. It has been assumed that factors related to the design of the landfill and the nature of the waste stored will provide a more reliable estimate of the risk of groundwater contamination. The factors ultimately adopted for assessment purposes are the type of waste $(T)$, the method of insulating the landfill from the ground $(I)$, the method of covering the waste $(C)$ and the degree of compaction $(\mathrm{Cmp})$.

The degree of impact of individual factors varies, which is expressed by their weights (from 1 to 5). Weights of $5\left(I_{w}, C_{w}\right)$ or $3\left(T_{w}, C m p_{w}\right)$ were assumed for individual factors. Each factor can have a value (rank) in the range from 0.1 to 1 (Table 5). The potential impact of a non-inert waste landfill on groundwater is determined by the $I_{l}$ index:

$$
I_{I}=T_{r} \cdot T_{w}+I_{r} \cdot I_{w}+C_{r} \cdot C_{w}+C m p_{r} \cdot C m p_{w}
$$


Depending on the $I_{l}$ index value calculated, the probability of an unwanted event $(P A)$ for a landfill and a non-inert waste heap is estimated accordingly (Table 5).

Table 5. Criteria for assessing and ranking factors affecting the risk of groundwater contamination as a result of the potential impact of a landfill and the relationship between $P A$ and $I_{l}$

\begin{tabular}{|c|c|}
\hline Criterion, factor & Rank \\
\hline $\begin{array}{l}\text { Waste type } \\
\text { - municipal } \\
\text { - } \text { hazardous/toxic }\end{array}$ & $\begin{array}{l}T_{r} \\
0.5 \\
1.0 \\
\end{array}$ \\
\hline $\begin{array}{l}\text { Manner of insulation from the ground } \\
\text { - double insulation: alternating } 2 \times \text { synthetic material (PVC, HDPE), } 2 \times \text { compacted } \\
\text { clay (thickness } \geq 1 \mathrm{~m}, k^{*} \leq 1 \cdot 10^{-9} \mathrm{~m} / \mathrm{s} \text { ), drainage } \\
\text { - } \quad \text { synthetic material (PVC, HDPE), compacted clay (thickness } \geq 1 \mathrm{~m}, \\
k \leq 1 \cdot 10^{-9} \mathrm{~m} / \mathrm{s} \text { ), drainage } \\
\text { - } \text { compacted clay (thickness } \geq 1 \mathrm{~m}, k \leq 1 \cdot 10^{-9} \mathrm{~m} / \mathrm{s} \text { ), drainage } \\
\text { - no insulation }\end{array}$ & $\begin{array}{l}0.7 \\
1.0\end{array}$ \\
\hline $\begin{array}{l}\text { Waste covering } \\
\text { - } \quad \text { synthetic material (PVC, HDPE), compacted clay (thickness } \geq 0.5 \mathrm{~m} \text {, } \\
\quad k>1 \cdot 10^{-9} \mathrm{~m} / \mathrm{s} \text { ), soil, drainage } \\
\text { - } \quad \text { clay (thickness } \geq 0.5 \mathrm{~m}, k>1 \cdot 10^{-9} \mathrm{~m} / \mathrm{s} \text { ), soil, drainage } \\
\text { - } \quad \text { loam (thickness } \geq 0.5 \mathrm{~m}, k>1 \cdot 10^{-7} \mathrm{~m} / \mathrm{s} \text { ), soil, drainage } \\
\text { - } \quad \text { soil only or no cover }\end{array}$ & $\begin{array}{l}0.4 \\
0.7 \\
1.0 \\
\end{array}$ \\
\hline $\begin{array}{l}\text { Waste compaction } \\
\text { - compacted, multiple compactor passes or permanent waste solidification } \\
\text { - } \text { poorly compacted, a few compactor passes or partial waste solidification } \\
\text { - non-compacted or non-solidified }\end{array}$ & $\begin{array}{c}C m p_{r} \\
0.5 \\
0.8 \\
1.0\end{array}$ \\
\hline $\begin{array}{ll}\text { - } & <5 \\
\text { - } & 5-10 \\
\text { - } & 10-15 \\
\text { - } & >15\end{array}$ & $\begin{array}{l}P A \\
0.2 \\
0.4 \\
0.6 \\
1.0\end{array}$ \\
\hline
\end{tabular}

${ }^{*} k$ is the hydraulic conductivity. 


\section{Step II - quantitative calculation of PA}

For industrial and infrastructure PSCs, an unwanted event is the worst-case emission of a contaminant to groundwater among the emissions possible for a given PSC. The probability has been quantitatively estimated:

$$
P A=P A_{B Z} \cdot P S F
$$

where $P A_{B Z}$ is the probability of failure occurrence for a given PSC (Eq. 6); $P S F$ is the combined probability of security failure, i.e., the failure of individual independent fail-safe protections (Eq. 7).

$$
P A_{B Z}=\max \left(P a_{i} \cdot \max P c_{j}\right)
$$

where $P a_{i}$ is the probability of occurrence of the accident initiating the emission of a contaminant from a given PSC into the environment, $i$ is the number of the initiating accident in question; $P c_{j}$ is the probability of occurrence of situation conditioning the triggering of a given accident initiating the emission of a contaminant $\left(P a_{i}\right) ; j$ is the number of the situation conditioning a given initiating accident.

$$
P S F=\max P S F_{i}
$$

where $P S F_{i}$ is the probability of failure of the fail-safe protection in question; $i$ is the protection number; examples of protections are process automation, safety automation, an operator's or system's action, isolation or protection system, fail-safe protection procedure, etc.

\subsubsection{Fertilized agricultural areas}

The probability of nitrate emissions to groundwater from diffuse sources of pollution (fertilized areas) has been calculated in an approximate manner. Atmospheric nitrogen deposition has been disregarded, similarly as some processes resulting in nitrogen losses, such as volatilization (Søgaard et al. 2002; Huijsmans et al. 2003), surface runoff and soil erosion. It has been assumed 
that the predicted emission of nitrates to groundwater depends on the relationship between the predicted amount of nitrogen fertilization and the crops' ability to utilize it $\left(F_{N}\right)$. The predicted $F_{N}$ relationship was calculated as the difference between the total annual effective nitrogen load $\left(N_{a}\right)$ and the maximum annual nitrogen load that can be utilized by the crop species under the given agronomic conditions $\left(N_{d}\right)$ according to Eq. (8):

$$
F_{N}=N_{a}-N_{d}=N_{a n}+N_{a m}+N_{a s}-N_{d}
$$

where $N_{a n}$ is the effective nitrogen load from natural fertilization, $\mathrm{kg} \cdot \mathrm{ha}^{-1} \cdot \mathrm{y}^{-1}$ (Eq. 9), $N_{a m}$ is the nitrogen load from mineral fertilization, $\mathrm{kg} \cdot \mathrm{ha}^{-1} \cdot \mathrm{y}^{-1}$, and $N_{a s}$ is the effective nitrogen load contained in the soil, $\mathrm{kg} \cdot \mathrm{ha}^{-1} \cdot \mathrm{y}^{-1}($ Eq.10).

$$
N_{a n}=N_{n} \cdot \beta
$$

where $N_{n}$ is the dose of nitrogen from manure, $\mathrm{kg} \cdot \mathrm{ha}^{-1} \cdot \mathrm{y}^{-1}$, and $\beta$ is a correction coefficient that determines the effectiveness of nitrogen from manure relative to nitrogen from mineral fertilizers (Jensen 2013).

$$
N_{a s}=N_{s} \cdot \alpha
$$

where $N_{s}$ is the stock of mineral nitrogen in the soil, $\mathrm{kg} \cdot \mathrm{ha}^{-1} \cdot \mathrm{y}^{-1}$, and $\alpha$ is a correction coefficient which determines the effectiveness of soil nitrogen relative to nitrogen from mineral fertilizers (Stanford et al. 1973).

In order to obtain the total amount $N_{n}$ applied to crops in the GSPZ, the nitrogen loads produced by the animals reared in the region should be added together depending on the farming system. The total annual amounts of nitrogen from both types of fertilizers and soil nitrogen are divided by the area of fertilized land in the GSPZ in order to obtain nitrogen load per unit area.

The classification of PA in fertilized areas on the basis of the difference between the nitrogen fertilization level and its potential utilization by crops is presented in Table 6 . If $F_{N}$ is negative, this probability is low or very low $(P A \leq 0.3)$. Consequently, no adverse effect is assumed $(A E=$ $0)$, which means no risk to the well field $(R=0)$. 
Table 6. Classification of unwanted event probability in fertilized areas

\begin{tabular}{ccc}
\hline$F_{N}$ & \multicolumn{2}{c}{ PA } \\
\cline { 2 - 3 }$\left[\mathrm{kg} \cdot \mathrm{ha}^{-1} \cdot \mathrm{y}^{-1}\right]$ & value & characteristics \\
\hline \hline$F_{N} \leq-25$ & 0.1 & very low \\
\hline$-25<F_{N} \leq 0$ & 0.3 & low \\
\hline $0<F_{N} \leq 25$ & 0.5 & high \\
\hline $25<F_{N} \leq 50$ & 0.7 & very high \\
\hline$F_{N}>50$ & 0.9 & extremely high \\
\hline
\end{tabular}

\subsection{Adverse effect of an unwanted event}

The maximum concentration that a chemical emitted from the PSC can reach in the aquifer situated beneath this source $\left(c_{\max }\right)$ is the sum of the predicted injection concentration of the chemical transported through the vadose zone to groundwater $\left(c_{i n j}\right)$ and the concentration originally present in the aquifer due to geogenic and/or anthropogenic causes $\left(c_{0}\right)$. The injection concentration $\left(c_{i n j}\right)$ is the concentration in the water percolating through the vadose zone. The maximum concentration $\left(c_{\max }\right)$ that a chemical compound mass can reach in an aquifer:

$$
c_{\max }\left(Q_{f}+Q_{i}\right)=c_{0} \cdot Q_{f}+c_{i n j} \cdot Q_{i}
$$

hence:

$$
c_{\max }=\frac{c_{0} \cdot Q_{f}+c_{i n j} \cdot Q_{i}}{Q_{f}+Q_{i}}
$$

where $Q_{f}$ is the groundwater flux in aquifer and $Q_{i}$ is the flux of groundwater percolating through the vadose zone beneath the PSC.

The adverse effect of an unwanted event $(A E)$ means the potential contamination of groundwater flowing into the well field. This effect is determined by the ratio of the predicted concentration that a chemical released from the PSC may reach in the water abstracted from the well $\left(c_{w}\right)$ to its permissible concentration in drinking water $\left(c_{t r}\right)$ :

$$
c_{w} \leq c_{t r} \rightarrow A E=0 \text { (no adverse effect) }
$$




$$
c_{w}>c_{t r} \rightarrow A E=1 \text { (adverse effect present) }
$$

The permissible concentration limit of a chemical compound in drinking water $\left(c_{t r}\right)$ corresponds to the concentration stipulated in the relevant legal act for water directed to the water supply network after disinfection.

The concentration that a chemical compound emitted from a PSC can reach in water abstracted from the well $\left(c_{w}\right)$ depends on the maximum concentration in groundwater beneath the PSC $\left(c_{\max }\right)$ and the concentration originally present in the aquifer $\left(c_{0}\right)$ :

$$
c_{w}=\frac{c_{\max } \cdot\left(Q_{i}+Q_{f}\right)+c_{0} \cdot\left(Q_{w}-Q_{i}-Q_{f}\right)}{Q_{w}}
$$

where $Q_{w}$ is the well pumping rate.

The predicted maximum concentration reached by the contaminant $\left(c_{\max }\right)$ has been determined using an analytical method at the time when it reaches the groundwater table, taking into account the processes connected with the mass migration. Only the main elements of the complex mass migration process, namely advection, adsorption, degradation, and biodegradation are taken into account. Hydrodynamic dispersion is not taken into account - a simplified assumption is adopted that mass transport follows the piston-flow model. Assuming a linear model of adsorption on the solid phase of the soil, the mass transport retardation factor $\left(R_{f}\right)$ is defined as (Freeze and Cherry 1979):

$$
R_{f}=1+\frac{K_{d} \cdot \rho_{s}}{n_{e}}
$$

where $K_{d}$ is the distribution coefficient for the adsorption process $\left(\mathrm{dm}^{3} \cdot \mathrm{kg}^{-1}\right) ; \rho_{s}$ is the bulk density of the soil $\left(\mathrm{kg} \cdot \mathrm{dm}^{-3}\right) ; n_{e}$ is the effective porosity of the soil.

The predicted groundwater injection concentration for a degradable chemical migrating through the vadose zone $\left(c_{i n j}\right)$ is determined by a first-order reaction model:

$$
c_{i n j}=c_{S} \cdot e^{-k \cdot t_{V}}
$$




$$
k^{\prime}=\frac{\ln 2}{t_{0.5}}
$$

where $c_{s}$ is the concentration of the chemical compound in the PSC; $t_{V}$ is the time from the emission of the compound from the source until it reaches the groundwater table; $k^{\prime}$ is the first-order degradation constant; $t_{0.5}$ is the degradation half-life time.

For conservative compounds, the mass transport time through the vadose zone $\left(t_{V}\right)$, following the piston-flow model, is equal to the vertical seepage time for water:

$$
t_{V}=\frac{m_{v} \cdot \Theta_{S}}{I_{e}}
$$

where $m_{v}$ is the thickness of the vadose zone $(\mathrm{m}), \Theta_{s}$ is the soil moisture $(-), I_{e}$ is the effective infiltration of the solution in which the contaminant is dissolved $\left(\mathrm{m} \cdot \mathrm{y}^{-1}\right)$.

For a fertilized area, AE is determined if the PA is at least high (Fig. 1, Table 6). In order to obtain the predicted nitrate injection concentration $\left(\mathrm{mg} \cdot \mathrm{L}^{-1}\right)$ migrated from topsoil through the unsaturated zone to groundwater $\left(c_{N O 3}\right)$, equation was used:

$$
c_{i n j}=c_{N O_{3}}=\frac{F_{N}}{I_{e}} \cdot 0.443
$$

where $F_{N}$ is the predicted nitrogen load in excess of fertilization needs $\left(\mathrm{kg} \cdot \mathrm{ha}^{-1} \cdot \mathrm{y}^{-1}\right) ; 0.443$ is the conversion factor used with respect to the units of the parameters appearing in this equation, accounting for the ratio of equivalent weights of nitrogen and nitrates.

The nitrate injection concentration $\left(c_{N O 3}\right)$ is equal to the concentration of nitrate in the topsoil leachate, due to the assumed absence of denitrification and volatilization during transport through the vadose zone.

\subsection{Annoyance related to adverse effect}

The annoyance related to the adverse effect for users of the abstracted water $\left(A_{A E}\right)$ is determined on the basis of its duration. The duration of annoyance, or supply non-functioning $\left(t_{n f}\right)$, is assumed to be the number of days during which groundwater drawn from a well would be unfit for drinking 
and users would have to be temporarily supplied from another source, using e.g. water tankers. The annoyance of the adverse effect increases with the length of the period during which water supply must be interrupted (Table 7).

Table 7. Classification of annoyance of an adverse effect for a groundwater well

\begin{tabular}{ccc}
\hline \multirow{2}{*}{$t_{n f}[$ days $]$} & \multicolumn{2}{c}{$A_{A E}$} \\
\cline { 2 - 3 } & value & characteristics \\
\hline \hline$t_{n f}=0$ & 0 & none \\
\hline $1 \leq t_{n f} \leq 5$ & 1 & low \\
\hline $5<t_{n f} \leq 10$ & 2 & medium \\
\hline $10<t_{n f} \leq 20$ & 3 & high \\
\hline$t_{n f}>20$ & 4 & very high \\
\hline
\end{tabular}

The concentration of the contaminant at the time of reaching the well field $\left(c_{w}\right)$ can be determined analytically, taking into account the processes associated with mass migration in groundwater, but hydrodynamic dispersion may be disregarded. The mass transport time of conservative compounds dissolved in water to the well $\left(t_{L}\right)$ is equal to the groundwater flow time in the aquifer:

$$
t_{L}=\frac{L}{U}
$$

where $L$ is the distance between the well and the location where the contamination occurred at the maximum concentration $\left(c_{\max }\right)[\mathrm{m}]$, and $U$ is the groundwater flow velocity $\left[\mathrm{m} \cdot \mathrm{y}^{-1}\right]$.

The predicted concentration of a chemical compound which is subject to degradation during transport in groundwater, determined at the time when it reaches the well $\left(c_{w}\right)$, is determined by a first-order degradation model:

$$
c_{w}=c_{\max } \cdot e^{-k \cdot t_{L}}
$$

The effect of sorption of inorganic constituents dissolved in water has been estimated using the method described above for downward transport trough the vadose zone. 


\section{MATERIALS}

\subsection{Adopted model}

In order to illustrate the application of the method presented, a risk analysis for a groundwater well field has been conducted for an idealized model in which frequently occurring selected types of human pressure and typical hydrogeological conditions have been assumed (Fig. 2). The phreatic aquifer is unconfined and has a hydraulic conductivity $k=10 \mathrm{~m} \cdot \mathrm{d}^{-1}$, a thickness $m=7 \mathrm{~m}$, and a hydraulic gradient $I=0.1 \%$. In the vadose zone with a thickness $m_{v}=4 \mathrm{~m}$, silty and loamy sand is present with a volumetric moisture $\Theta_{s}=0.2$ (based on Witczak et al. 2011). The precipitation is $P$ $=0.65 \mathrm{~m} \cdot \mathrm{y}^{-1}$. Recharge has been estimated using a infiltration method (Staśko et al. 2012) according to Eq. (23):

$$
I_{e}=P \cdot \omega
$$

where $\omega$ is the effective infiltration coefficient of precipitation (for topsoil $\omega=0.20$, for compacted municipal waste in a landfill $\omega=0.30)$.

Several PSCs are present within the well catchment. These are point sources, i.e., gas stations, industrial plants, landfills, and farms - PSC Nos $1 \div 9$, and also agricultural areas fertilized with nitrogen where different crops are grown - I, II and III (Table 8, Tables S1 and S2 in the Supplementary Material). In the model described the values of individual factors affecting the probability of an unwanted event from PSCs are not actual values, but rather figures adopted in order to better illustrate the issue. 


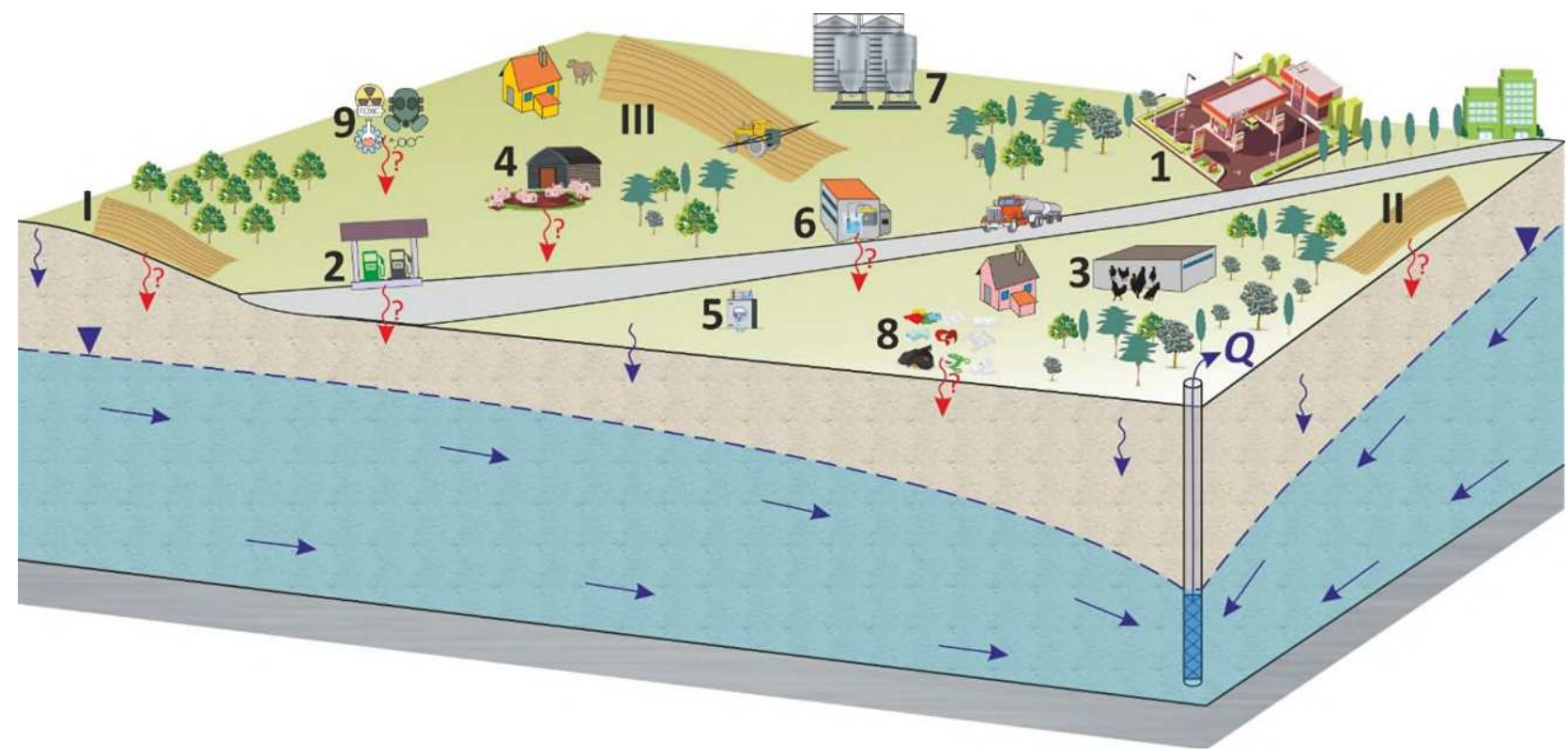

Fig. 2 Schematic 3D cross-section of the example test site (not to scale). PSCs are numbered in accordance with Tables 8 and S1

Table 8. The risk caused by a given PSC estimated on the basis of the $P A$ qualitative assessment (see Table S1 to PSCs characteristics and assumed values of factors affecting the risk)

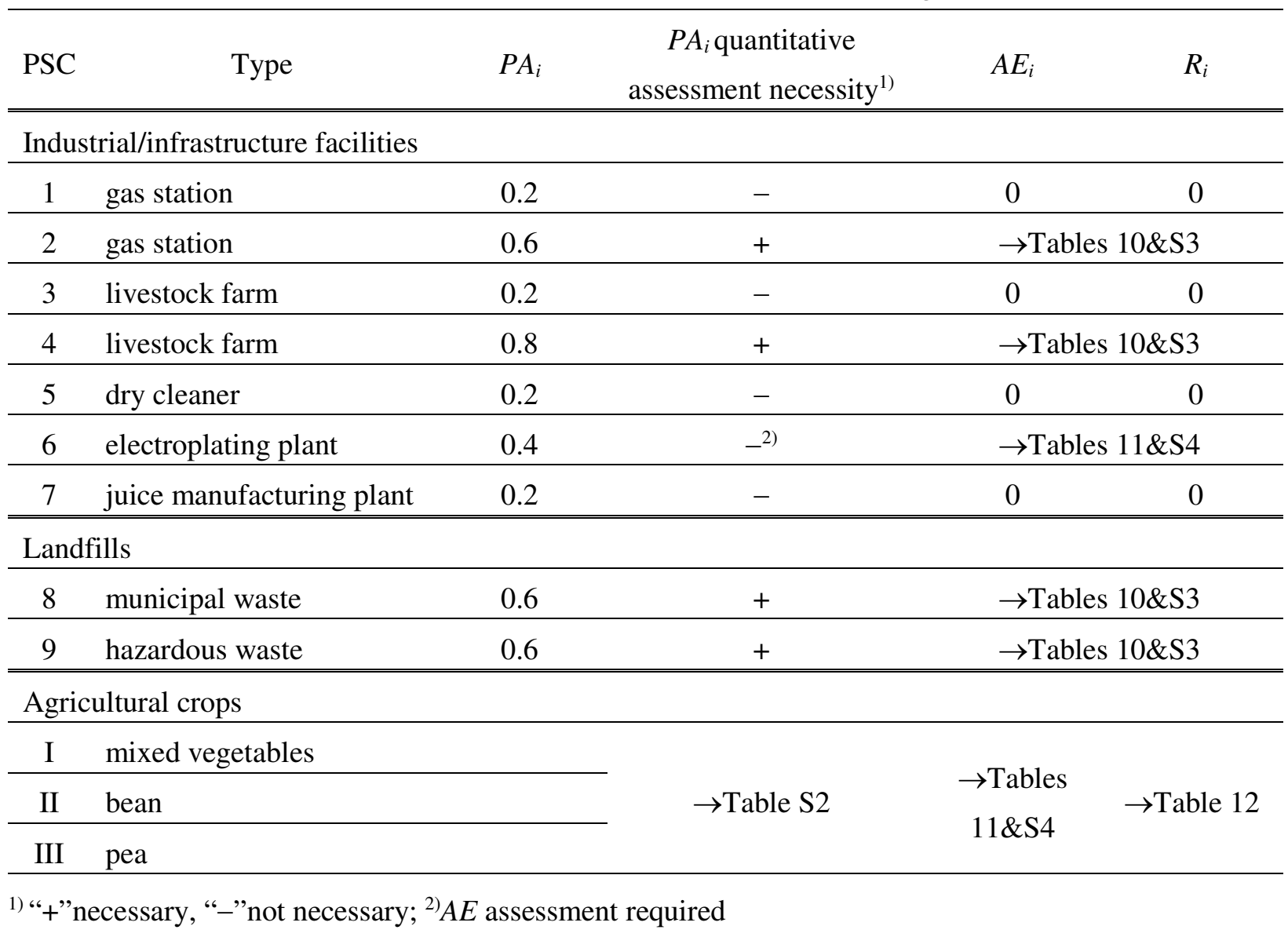




\subsection{Sensitivity analysis}

In order to analyze the sensitivity of the GSRA method used to the variation in the values of the parameters used, an assessment of AE has been performed under three scenarios (Table 9). The adverse effect analysis concerned those PSCs for which PA indicated that this analysis was necessary. It has been assumed that the differences between the scenarios analyzed would concern the set of PSCs analyzed and the amount of water abstracted from the well field. The sensitivity analysis for PSC No 8 include two sub-options: 8.1 and 8.2 (greater amount of waste in the landfill in sub-option 8.2 compared to 8.1). It has been assumed that the variation in well yield determines the degree of contaminant mass dilution in the water pumped from the well and the extent of the well catchment.

Table 9. Scenarios assumed for the purposes of sensitivity analysis

\begin{tabular}{|c|c|c|c|}
\hline Scenario & PSC & Potential adverse impact & $\begin{array}{l}\text { Water } \\
\text { abstraction } \\
\left(\mathrm{m}^{3} \cdot \mathrm{d}^{-1}\right)\end{array}$ \\
\hline A & $6,8.1, \mathrm{II}$ & $\begin{array}{l}\text { moderate }- \text { concentration of sulfates in landfill leachate } \\
c_{s}=1,000 \mathrm{mg} \cdot \mathrm{L}^{-1} ; \text { three PSCs present }\end{array}$ & 1,000 \\
\hline B & $8.2, \mathrm{III}$ & $\begin{array}{l}\text { significant }- \text { higher sulfates concentration in landfill leachate } \\
c_{s}=2,000 \mathrm{mg} \cdot \mathrm{L}^{-1} \text {, higher waste volume, higher excess nitrogen } \\
\text { load from more intensive fertilization of crop III }\end{array}$ & 1,000 \\
\hline $\mathrm{C}$ & 8.1, II & limited & 100 \\
\hline
\end{tabular}

\section{RESULTS AND DISCUSSION}

For industrial and infrastructure PSCs, the first GSRA stage is a qualitative assessment of PA (Table 8). The assessment has demonstrated that for PSC No $6 P A=0.4$, indicating the need to assess the adverse effect. For PSCs for which the qualitatively estimated probability $P A>0.5$, it is necessary to proceed to the second stage of probability assessment (additional quantitative assessment). For such PSCs, possible failure initiating accidents and events that condition 
initiating accidents have been assumed, for which, in turn, the estimated occurrence probability values have been assumed $-P a_{i}$ and $P c_{j}$. Possible typical fail-safe protection have also been assumed together with the estimated probability $\left(P S F_{i}\right)$ of their failure or ineffectiveness (Table 10). In the example described the values of individual probabilities are not actual values obtained from source materials, but rather figures adopted in order to better illustrate the issue.

Quantitative assessment of PA for PSCs Nos 2, 4, and 9 has demonstrated that adequate fail-safe protections result in the absence of an adverse effect $(A E=0)$ and consequently the absence of risk $(R=0)$. For the municipal landfill $(8)$, given that it is certain that precipitation will infiltrate the landfill $\left(P c_{j}=1.0\right)$ and that it is not insulated, the probability $P A=1$, which necessitates adverse effect $(A E)$ assessment.

Table 10. The risk caused by a given PSC estimated on the basis of the PA quantitative assessment (evaluation details in Table S3)

\begin{tabular}{|c|c|c|c|c|c|c|}
\hline PSC and failure initiating accident & $P a_{i}$ & $P A_{B Z}$ & $P S F$ & $P A_{i}$ & $A E_{i}$ & $R_{i}$ \\
\hline \multicolumn{7}{|l|}{ 2. Gas station } \\
\hline damage to a gas pump & 0.01 & \multirow{2}{*}{0.0005} & \multirow{2}{*}{0.001} & \multirow{2}{*}{$5 \mathrm{E}-7$} & \multirow{2}{*}{0} & \multirow{2}{*}{0} \\
\hline leak from fuel tank & 0.01 & & & & & \\
\hline \multicolumn{7}{|l|}{ 4. Livestock farm } \\
\hline $\begin{array}{l}\text { leaking insulation of the slurry } \\
\text { and dung storage area }\end{array}$ & 0.25 & 0.125 & 0.01 & 0.00125 & 0 & 0 \\
\hline \multicolumn{7}{|l|}{ 8. Municipal waste landfill } \\
\hline $\begin{array}{l}\text { no insulation from the ground, } \\
\text { no cover }\end{array}$ & 1.0 & 1.0 & & 1.0 & \multicolumn{2}{|c|}{$\begin{array}{l}\rightarrow \text { Tables } \\
11 \& S 4\end{array}$} \\
\hline \multicolumn{7}{|l|}{ 9. Hazardous waste landfill } \\
\hline ground insulation leaking & 0.1 & \multirow{2}{*}{0.001} & \multirow{2}{*}{0.05} & \multirow{2}{*}{$5 \mathrm{E}-5$} & \multirow{2}{*}{0} & \multirow{2}{*}{0} \\
\hline landfill drainage damage & 0.05 & & & & & \\
\hline
\end{tabular}

For agricultural crops, a quantitative assessment of PA is presented in Table S2. For type II and III crops, the calculated excess nitrogen loads $F_{N}$ are high. This is due to the relatively low nitrogen utilization capacities of these vegetables compared to other typical crops. As a result, for both crops 
the quantitatively calculated PA is extremely high $(P A=0.9)$, and thus it is necessary to assess the AE.

The adverse effect assessment has been performed under the three scenarios adopted for analyzing the sensitivity of the method (Tables 9 and 11).

Table 11. Assessment of the adverse effect of the possible events detected at the stage of assessing the PA (evaluation details in Table S4)

\begin{tabular}{|c|c|c|c|c|c|}
\hline Scenario & $\begin{array}{l}\text { PSC } \\
\text { and threat form }\end{array}$ & $\begin{array}{l}\text { Contaminant and } \\
\text { its concentration } \\
\quad \text { in } \operatorname{PSC}\left(c_{s}\right)\end{array}$ & $\begin{array}{c}\text { Concen- } \\
\text { tration } \\
\text { in well }\left(c_{w}\right)\end{array}$ & $\begin{array}{c}\text { Threshold } \\
\text { concentration in } \\
\text { drinking water } \\
\qquad\left(c_{t r}\right)^{1)}\end{array}$ & $A E_{i}$ \\
\hline & & $\mathrm{mg} \cdot \mathrm{L}^{-1}$ & $\mathrm{mg} \cdot \mathrm{L}^{-1}$ & $\mathrm{mg} \cdot \mathrm{L}^{-1}$ & \\
\hline \multirow{3}{*}{ A } & $\begin{array}{c}8.1 \\
\text { leachate }\end{array}$ & $\begin{array}{l}\text { sulfate } \\
1,000^{2)}\end{array}$ & 70.3 & 250 & 0 \\
\hline & $\begin{array}{c}6 \\
\text { chromium plating bath }\end{array}$ & $\begin{array}{l}\text { chromium } \\
20,000^{3)}\end{array}$ & 0.001 & 0.05 & 0 \\
\hline & $\begin{array}{c}\text { crop II } \\
\text { topsoil leachate, nitrogen load surplus }{ }^{4)}\end{array}$ & $\begin{array}{l}\text { nitrate } \\
485^{5)}\end{array}$ & 6.2 & 50 & 0 \\
\hline \multirow{2}{*}{ B } & $\begin{array}{c}8.2 \\
\text { leachate }\end{array}$ & $\begin{array}{l}\text { sulfate } \\
2,000\end{array}$ & 258.4 & 250 & 1 \\
\hline & $\begin{array}{c}\text { crop III } \\
\text { topsoil leachate, nitrogen load surplus }{ }^{4)}\end{array}$ & $\begin{array}{l}\text { nitrate } \\
741^{5)}\end{array}$ & 53.7 & 50 & 1 \\
\hline \multirow{2}{*}{$\mathrm{C}$} & $\begin{array}{c}8.1 \\
\text { leachate }\end{array}$ & $\begin{array}{l}\text { sulfate } \\
1,000\end{array}$ & 253.0 & 250 & 1 \\
\hline & $\begin{array}{c}\text { crop II } \\
\text { topsoil leachate, nitrogen load surplus }{ }^{4)}\end{array}$ & $\begin{array}{l}\text { nitrate } \\
485^{5)}\end{array}$ & 52.7 & 50 & 1 \\
\hline
\end{tabular}

\section{$\underline{\text { Scenario A }}$}

For PSC No 6 the calculated vertical migration time through the vadose zone for chromium, taking into account the delay due to sorption, amounts to $t_{v C r}=26.3$ years. This indicates the key role of 
sorption in $A E$ risk assessment since the calculated chromium concentration value in the well 25 years after the potential leakage in such a PSC is still lower than the permissible value in drinking water. This means no adverse effect and no risk to the well from this PSC over the assumed time horizon (Table 12).

For PSC No 8.1, sulfate concentration in well water is lower than the permissible limit for drinking water. This means no adverse effect and no risk to the well field. This is due to a reduction in sulfate concentration during transport to the well as a result of leachate being diluted after being mixed with clean waters of the influent stream.

For crop No II, the predicted nitrate concentration in well water does not exceed the permissible limit for drinking water, indicating no adverse effect and consequently no risk to the well field from this PSC. This is due to the reduction in contaminant concentration due to the mixing of leachate from the fertilized crop with the water flowing into the aquifer.

Table 12. Summary of GSRA results

\begin{tabular}{|c|c|c|c|c|c|c|c|}
\hline PSC No & 6 & 8.1 & 8.2 & II & III & $R$ & GSPZ establishment \\
\hline \multicolumn{8}{|c|}{ Scenario A } \\
\hline$L U_{i}$ & 4 & 4 & - & 4 & - & \multirow{3}{*}{0} & \multirow{3}{*}{ not required } \\
\hline$A_{A E i}$ & 0 & 0 & - & 0 & - & & \\
\hline$R_{i}$ & 0 & 0 & - & 0 & - & & \\
\hline \multicolumn{8}{|c|}{ Scenario B } \\
\hline$L U_{i}$ & - & - & 4 & - & 4 & \multirow{3}{*}{16} & \multirow{3}{*}{ required } \\
\hline$A_{A E i}$ & - & - & 4 & - & 4 & & \\
\hline$R_{i}$ & - & - & 16 & - & 16 & & \\
\hline \multicolumn{8}{|c|}{ Scenario C } \\
\hline$L U_{i}$ & - & 4 & - & 4 & - & \multirow{3}{*}{16} & \multirow{3}{*}{ required } \\
\hline$A_{A E i}$ & - & 4 & - & 4 & - & & \\
\hline$R_{i}$ & - & 16 & - & 16 & - & & \\
\hline
\end{tabular}




\section{$\underline{\text { Scenarios B and C }}$}

The results obtained for both scenarios are similar and indicate a threat to the well field from the landfill under options 8.1 and 8.2, and from crops II and III (Table 11 and 12). As the landfill is not insulated from the ground, the adverse effect of its impact under both options will be permanent, resulting in the need for the wells to be shut down for a long time. This would create a very high annoyance to water users, hence $A_{A E i}=4$ has been adopted. As a consequence, the projected risk to the well field from this PSC will be $R_{i}=16$. Similarly for crops: since crops II and III are perennial, the adverse effect of excess fertilization with nitrogen will also persist over many years, requiring long-term closure of the well field. This situation causes a very high annoyance to water users $\left(A_{A E i}\right.$ =4), so $R_{i}=16$.

Scenario B indicates that despite the unchanged amount of water flowing into the well compared to Scenario A, there is an adverse effect of PSC impact and, as a consequence, risk to the well field. This is the effect of human pressure in scenario B, i.e.: the higher concentration of contaminant in the leachate present under the larger landfill, a larger cultivation area, and the adoption in the analysis of crop III, which is characterized by a lower maximum effective nitrogen load than crop II, which was adopted in scenario A.

In addition to the magnitude of the contaminant load dissolved in leachate from these PSCs, the ratio of the amount of water pumped through the well to the amount of water flowing from under the PSCs into the well plays an important role in assessing the threat to the well field. The difference between these figures is the amount of uncontaminated groundwater inflow. Under scenario A, the considerable amount of water abstracted from the well results in the contaminant plume being significantly diluted by the water flowing laterally into the well from the entire well catchment. As a result, the averaged contaminant concentration in the water flowing to the well is lower than its concentration in the water flowing to a well from which less water is abstracted. Under scenario C, the inflow of uncontaminated groundwater from outside the PSCs threatening the well field is low. 
As a result, the proportion of contaminant in the water flowing into the well will be higher and consequently the risk will increase. Where the amount of abstracted water is low, even a small local PSC can pose a large risk to the well field. Nevertheless, a proper GSRA should also take into account the analysis of hydrogeological conditions and the distribution of the hydrodynamic field for the assumed well yield, which significantly affects the extent and shape of the WHPA.

The probability of groundwater contamination as a result of over-fertilization in agricultural areas may vary with time, depending on the changes in crop species. The total nitrogen load from different types of manure from different species of livestock may also vary. Types and amounts of mineral fertilizers may vary as well. The probability of exceeding the fertilizer dosage prescribed rates may also exhibit spatial variation depending on the crop species grown, the soil category and the nitrogen load originating from different sources in individual GSPZ regions. In order for total nitrogen loads to be predicted as accurately as possible, analyses should be carried out for individual agricultural sub-areas.

The above considerations indicate that it is important to optimize the amount of water abstracted from the well or distribute water abstraction between individual wells in a multi-well field as well as to optimize nitrogen fertilization in order to protect well fields against high risk resulting in their closure (Salcedo-Sanchez et al. 2013; Zdechlik and Kałuża 2019).

Where a contaminant is continuously emitted to groundwater, the annoyance for water users plays a key role in the assessment of the resulting risk. The outcome of the risk analysis also depends on the degree of adverse impact of PSCs. The projected very high annoyance to users and the significant degree of adverse impact make it necessary to establish a GSPZ to prevent the degradation in groundwater quality. 


\section{CONCLUSIONS}

Although the method proposed is extensive, the GSRA results obtained as a result of its use should provide a robust basis for policymakers when making decisions on GSPZ establishment.

As the GSRA performed concerns a specific time span, another analysis will be required after this period. This is due to possible changes in land use, the technical condition of the PSCs, agricultural production and the related fertilization.

The reliable performance of a GSRA requires the involvement of a multidisciplinary team and is a difficult task. The complexity of the analysis depends on the manner of land use assessment and the diversity of PSCs within the projected GSPZ.

It is also necessary to improve the methods for adapting assessments of the probability of industrial accidents as well as of adverse natural, economic, and legal events to environmental risk analyses. This issue, although very difficult, must be resolved because without taking these probabilities into account, the assessments will inevitably be burdened by uncertainty.

The proposed process-based holistic GSRA method, which takes into account different types of PSCs, can be also applied with minor modifications to regional analysis of groundwater contamination risk. Assessing the need for groundwater protection on the regional scale is important in the light of the progressing depletion of its resources. 


\section{Supplementary Information}

The online version contains supplementary material available at ...

\section{Authors Contributions}

Robert Duda and Robert Zdechlik designed the study. Robert Zdechlik prepared the data for analysis and conducted the research. Jarosław Kania participated in the research. Robert Duda wrote the first draft of the manuscript, which was edited and enhanced by Robert Zdechlik. All authors contributed to reviewing the manuscript.

\section{Funding}

This research was supported by Ministry of Education and Science, Poland - Grant No.

16.16.140.315.

Data Availability: Yes.

Code Availability: Not applicable.

\section{Compliance with Ethical Standards}

Ethical Approval: $\quad$ All work is compliance with Ethical Standards.

Consent to Participate: Authors give their permission.

Consent to Publish: $\quad$ Authors give their permission.

Competing Interests: The authors declare no competing interests.

Conflict of Interest: $\quad$ The authors declare no conflict of interest. 


\section{REFERENCES}

Duda R, Klebert I, Zdechlik R (2020) Groundwater pollution risk assessment based on vulnerability to pollution and potential impact of land use forms. Pol J Environ Stud 29(1):87-99. https://doi.org/10.15244/pjoes/104362.

Enzenhoefer R, Binning PJ, Nowak W (2015) STakeholder-Objective Risk Model (STORM): Determining the aggregated risk of multiple contaminant hazards in groundwater well catchments. Adv Water Resour 83:160-175. https://doi.org/10.1016/j.advwatres.2015.05.015

Enzenhoefer R, Nowak W, Helmig R (2012) Probabilistic exposure risk assessment with advective-dispersive well vulnerability criteria. Adv Water Resour 36:121-132. https://doi.org/10.1016/j.advwatres.2011.04.018

Freeze RA, Cherry JA (1979) Groundwater. Prentice-Hall, Englewood Cliffs, New Jersey Huan H, Hu L, Yang Y, Jia Y, Lian X, Ma X, Jiang Y, Xi B (2020) Groundwater nitrate pollution risk assessment of the groundwater source field based on the integrated numerical simulations in the unsaturated zone and saturated aquifer. Environ Int 137:105532. https://doi.org/10.1016/j.envint.2020.105532

Huan H, Wang J, Lai D, Teng Y, Zhai Y (2015) Assessment of well vulnerability for groundwater source protection based on a solute transport model: a case study from Jilin City, northeast China. Hydrogeol J 23(3):581-596. https://doi.org/10.1007/s10040-014-1211-4

Huan H, Zhang BT, Kong H, Li M, Wang W, Xi B, Wang G (2018) Comprehensive assessment of groundwater pollution risk based on HVF model: A case study in Jilin City of northeast China. Sci Total Environ 628-629:1518-1530. https://doi.org/10.1016/j.scitotenv.2018.02.130

Huijsmans JFM, Hol JMG, Vermeulen GD (2003) Effect of application method, manure characteristics, weather and field conditions on ammonia volatilization from manure applied 
to arable land. Atmos Environ 37:3669-3680. https://doi.org/10.1016/S13522310(03)00450-3

Jensen LS (2013) Animal manure fertiliser value, crop utilisation and soil quality impacts. In: Animal Manure Recycling: Treatment and Management. Sommer SG, Christensen ML, Schmidt T, Jensen LS (eds), John Wiley \& Sons. https://doi.org/10.1002/9781118676677.ch15

Li F, Zhao Y, Feng P, Zhang W, Qiao J (2015) Risk assessment of groundwater and its application. Part I: risk grading based on the functional zoning of groundwater. Water Resour Manag 29(8):2697-2714. https://doi.org/10.1007/s11269-015-0964-4

Li F, Zhu J, Deng X, Zhao Y, Li S (2018) Assessment and uncertainty analysis of groundwater risk. Environ Res 160:140-151. https://doi.org/10.1016/j.envres.2017.09.030

Locatelli L, Binning PJ, Sanchez-Vila X, Lemming Søndergaard G, Rosenberg L, Bjerg PL (2018) A simple contaminant fate and transport modelling tool for management and risk assessment of groundwater pollution from contaminated sites. J Contam Hydrol 221:35-49. https://doi.org/10.1016/j.jconhyd.2018.11.002

Modarres M, Kim IS (2020) Probabilistic risk assessment. In: Reference module in Earth systems and environmental sciences, Elsevier. https://doi.org/10.1016/B978-0-12-409548-9.12161-X Najdeker E (1997) Trivalent chromium plating baths, 1. Literature overview and primary investigations. Materialy Elektroniczne, 25(2):26-34 (in Polish)

Ostrom L, Wilhelmsen C (2019) Probabilistic risk assessment. In: Risk assessment - tools, techniques, and their applications. 251-260, John Wiley \& Sons. https://doi.org/10.1002/9781119483342.ch18

Pietrucin D (2013) Monitoring of the aquatic environment of an industrial area with multiple sources of pollution. Bulletin of Geography, Physical Geography Series 6:43-58. https://doi.org/10.2478/bgeo-2013-0003. 
Rodak C, Silliman S (2012) Probabilistic risk analysis and fault trees: Initial discussion of application to identification of risk at a wellhead. Adv Water Resour 36:133-145. https://doi.org/10.1016/j.advwatres.2011.02.005

Salcedo-Sanchez ER, Esteller MV, Garrido Hoyos SE, Martinez-Morales M (2013) Groundwater optimization model for sustainable management of the Valley of Puebla aquifer, Mexico. Environ Earth Sci 70:337-351. https://doi.org/10.1007/s12665-012-2131-z

Søgaard HTS, Sommer SG, Hutchings NJ, Huijsmans JFM, Bussink DW, Nicholson F (2002) Ammonia volatilization from field-applied animal slurry - the ALFAM model. Atmos Environ 36:3309-3319. https://doi.org/10.1016/S1352-2310(02)00300-X

Stanford G, Legg JO, Smith SJ (1973) Soil nitrogen availability evaluations based on nitrogen mineralization potentials of soils and uptake of labeled and unlabeled nitrogen by plants. Plant Soil 39:113-124. https://doi.org/10.1007/BF00018050

Staśko S, Tarka R, Olichwer T (2012) Groundwater recharge evaluation based on the infiltration method. In: Maloszewski P, Witczak S, Malina G (eds), Groundwater Quality Sustainability. International Association of Hydrogeologists, Selected Papers, 17:189-197

Su X, Wang H, Zhang Y (2013) Health risk assessment of nitrate contamination in groundwater: a case study of an agricultural area in northeast China. Water Resour Manag 27:3025-3034. https://doi.org/10.1007/s11269-013-0330-3

Teng YG, Zuo R, Xiong Y, Wu J, Zhai YZ, Su J (2019) Risk assessment framework for nitrate contamination in groundwater for regional management. Sci Total Environ 697:134102. https://doi.org/10.1016/j.scitotenv.2019.134102

Troldborg M, Binning PJ, Nielsen S, Kjeldsen P, Christensen AG (2009) Unsaturated zone leaching models for assessing risk to groundwater of contaminated sites. J Contam Hydrol 105:28-37. https://doi.org/10.1016/j.jconhyd.2008.11.002 
Twardowska I (2004) Assessment of pollution potential from solid waste. In: Twardowska I,

Allen HE, Kettrup AF, Lacy WJ (eds) Solid waste: assessment, monitoring and remediation.

Waste Management Series, 4, Elsevier, Amsterdam

WHO (2017a) Global status report on water safety plans: A review of proactive risk assessment and risk management practices to ensure the safety of drinking-water. World Health Organization, Geneva. https://apps.who.int/iris/handle/10665/255649

WHO (2017b) Guidelines for drinking-water quality: Fourth edition incorporating the first Addendum. World Health Organization, Geneva. https://www.who.int/publications/i/item/9789241549950

Witczak S, Duda R, Żurek A, Górski J, Dragon K et al (2011) Groundwater vulnerability map of Poland, 1:500 000. Ministry of Environment, Publ. by AGH University of Science and Technology, Krakow, (in Polish with English translation)

Zdechlik R, Kałuża A (2019) The FEM model of groundwater circulation in the vicinity of the Świniarsko intake, near Nowy Sącz (Poland). Geologos 25:255-262.

https://doi.org/10.2478/logos-2019-0028

Zhang B, Li G, Cheng P, Yeh T-CJ, Hong M (2016) Landfill risk assessment on groundwater based on vulnerability and pollution index. Water Resour Manag 30:1465-1480. https://doi.org/10.1007/s11269-016-1233-X 


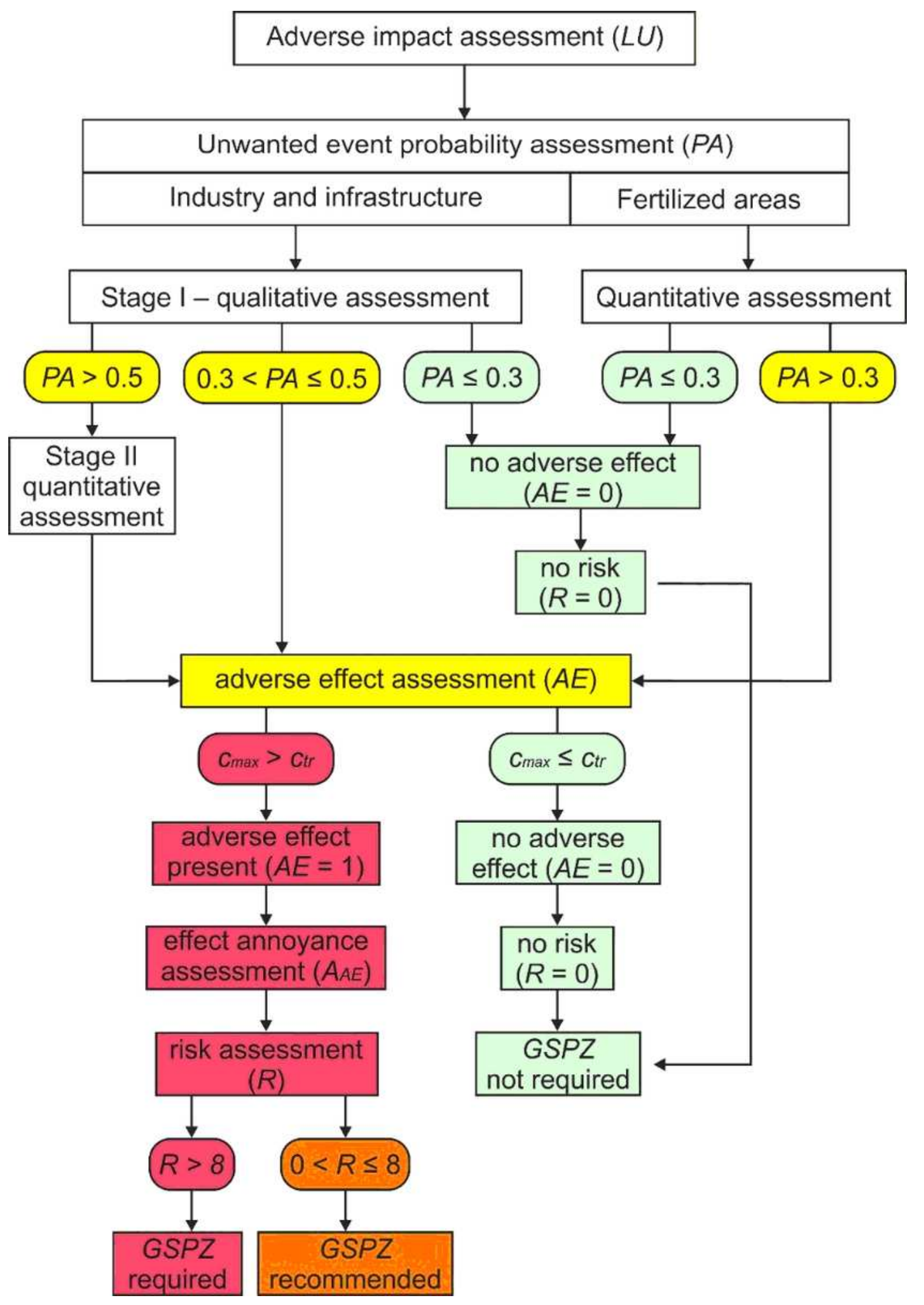

Figure 1

Flowchart of GSRA application 


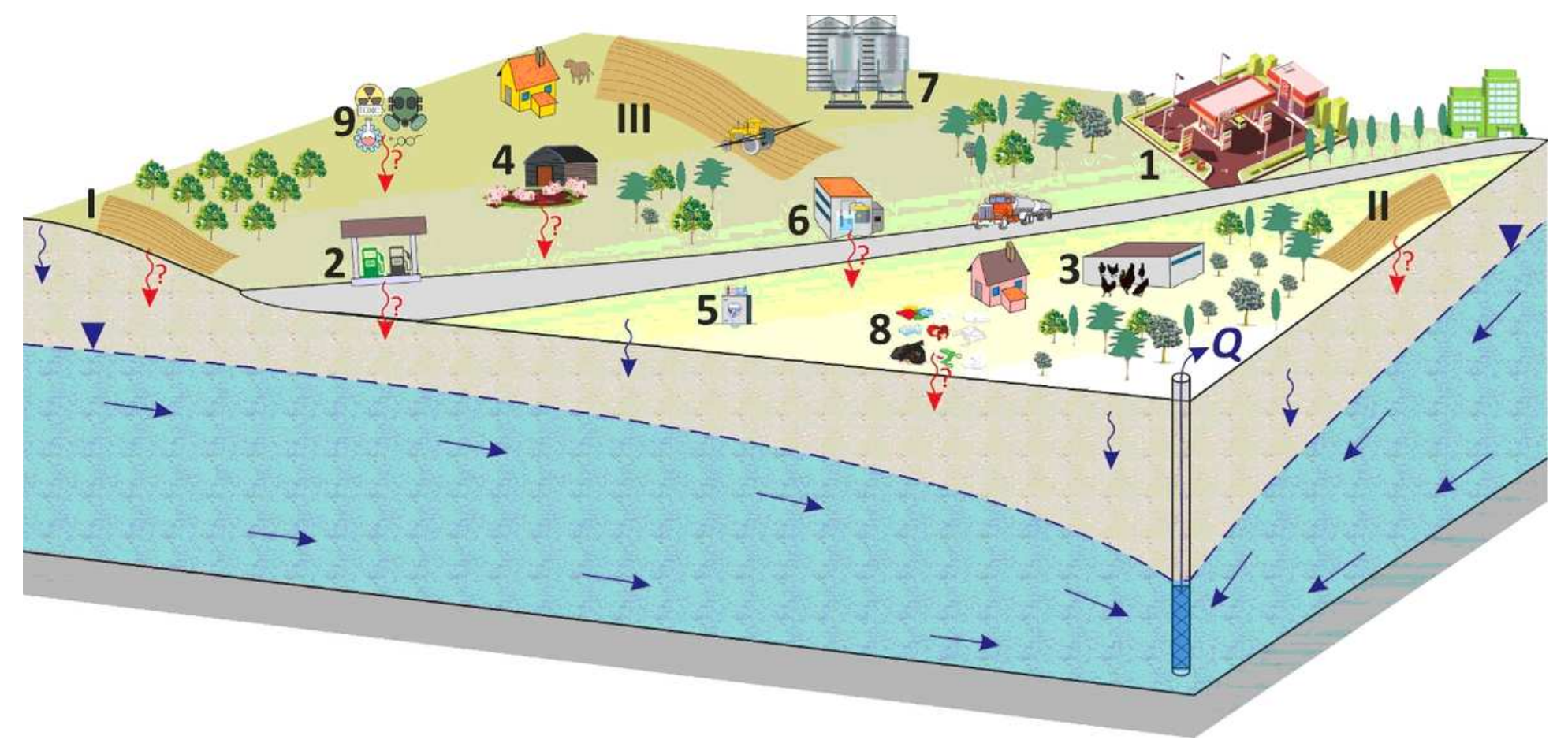

Figure 2

Schematic 3D cross-section of the example test site (not to scale). PSCs are numbered in accordance with Tables 8 and S1

\section{Supplementary Files}

This is a list of supplementary files associated with this preprint. Click to download.

- Dudaetal20210412WARMSupplementarymaterial.docx 